\title{
EU-China relations in the time of COVID-19
}

\section{Nicolas Chapuis ${ }^{1}$}

Published online: 22 May 2020

(C) Springer-Verlag GmbH Germany, part of Springer Nature 2020

As recently as mid-January, the year 2020 had been hailed as a crucial one for EUChina relations, with two summits scheduled to take place, one in Beijing in March and another in Leipzig in September, as well as numerous other high-level meetings on various issues from economic and political to climate action and human rights.

The outbreak of the coronavirus in China, and its subsequent spread to the rest of the world over the past three months, has meant that our pre-existing plans for deepening EU-China cooperation have been temporarily side-tracked as both the EU and China are fully mobilised to tackle what has now become a truly global problem.

It is already clear that the pandemic will reshape our world. But precisely how will depend on the choices that we make today. The coronavirus should be seen as the world's common enemy. It is clear that a global pandemic requires a global response.

The European Union is playing its role and doing everything possible to tackle the crisis and its consequences. We are acting with determination to protect our citizens, public health, and avoid further spreading, as well as helping to alleviate the dramatic economic consequences this crisis will have globally. With our partners around the world, we are developing a common international approach to fight the pandemic, and to assist the most vulnerable, not least those in developing countries and conflict zones. The guiding principles for this global effort should be partnership, solidarity, and transparency.

EU High Representative for Foreign Affairs and Security Policy Josep Borrell pointed out recently that there are four major priorities for global cooperation:

First, we must pool resources to produce new treatments and a vaccine, which should be regarded as a global public good. The EU has already launched several actions to tackle the current outbreak of the novel coronavirus. The EU has put together $€ 140$ million to search for rapid point-of-care diagnostic tools, new treatments, and new vaccines. Already four Chinese entities are participating in three research projects from this funding. In the end, we can expect a total envelope of around 300 million euros

Nicolas Chapuis is the Ambassador of the European Union to the People's Republic of China.

Nicolas Chapuis

delegation-china@eeas.europa.eu

1 Delegation of the European Union to the People's Republic of China, Beijing, China 
from the European Commission to fund medical research against COVID-19. More might come later.

Second, we need to limit the economic damage by coordinating fiscal and monetary stimulus measures and protecting the global trade in goods. We are already taking significant steps to mitigate the economic fallout by taking various steps at EU and Member State level to save people's jobs and to support companies hit by the crisis. We count on China to work with us in framing a globally coordinated economic recovery strategy.

Third, we should be planning to re-open borders in a coordinated way whenever health authorities give the green light. Also, any loosening of confinement should be gradual and measures concerning a large number of people should progressively be replaced by targeted ones involving the most vulnerable.

Finally, we must cooperate to fight disinformation campaigns. There is a geopolitical component including a struggle for influence through fake news, aggressive spinning, half-truths, and, sometimes, outright lies. Some are abusing the pandemic to advance their political goals.

It is important to be clear that at different stages of the pandemic, there has been reciprocal assistance between Europe, China, and others, demonstrating mutual support. The EU supported China when it was overwhelmed by the outbreak at the beginning of the year with large donations of much-needed equipment, and now China is sending equipment and doctors to help affected countries around the world.

The EU recently committed a 20 billion euro package to support partner countries in the fight against the coronavirus pandemic and its consequences. The EU will help the most vulnerable countries in Africa; the EU's neighbourhood - the Western Balkans; the Eastern Partner countries; the Middle East and North Africa; parts of Asia and the Pacific; Latin America; and the Caribbean. It will focus also on the people most at risk, including children, women, the elderly, and disabled people, as well as migrants, refugees, internally displaced persons, and their host communities.

We count on all major global players to join us in assisting the most vulnerable to handle the pandemic and its consequences. In this context, on May 4, the EU hosted an online Global Pandemic Response Pledging Conference on Vaccines, Diagnostics, and Treatment, with the aim of raising billions of euro to enhance global preparedness and ensure adequate funding to develop and deploy a vaccine against COVID-19.

In addition to medical equipment, there is a real need for macro-economic assistance and significant debt relief for highly indebted countries. So once we join forces to beat back the virus, the next steps will be to join forces to forge a global economic recovery. The best way to accelerate the economic recovery is to expand trade. This is where, as major global players, successful cooperation on the EU-China bilateral front will be even more important. We will need more trade and investment on both sides, so a swift conclusion of negotiations on the EU-China Comprehensive Agreement on Investment will be crucial to this end.

But let us also cooperate to make this a green recovery. One of the major lessons from Nature is that the new virus outbreaks we have experienced since the turn of the century are the result of infringement of natural wildlife habitats which we should do more to protect. We have all seen refreshing examples from all over the world of a reduction in pollution due to diminished human activity. So let us join hands to invest in smart and green solutions for a more sustainable and healthy planet. 
Even if all efforts are now focused on combating the immediate crisis of COVID-19 and planning the necessary recovery, we will at some point have to draw lessons learned on the exact origin of the outbreak and its rapid spread across the world, with such devastating effects in terms of loss of lives and economic havoc. We will also need to enhance our collective preparedness against future pandemics and related threats, including through adequate reform of the WHO.

The world initially met the crisis in an uncoordinated fashion, with too many countries ignoring the warning signs and going it alone. It is now clear that the only way out of it is together.

Publisher's note Springer Nature remains neutral with regard to jurisdictional claims in published maps and institutional affiliations. 